\title{
Neonatal Near Miss and its associated factors at Injibara General Hospital, Awi Zone, Northwest Ethiopia, 2019
}

Habtamu Gebrehana Belay ( $\sim$ hgebrehana@yahoo.com )

Debre Tabor University

Simachew Kassa Limenih

Bahir Dar University

Toyiba Hiyaru Wassie

Bahir Dar University

Minale Bezie Ambie

Debre Tabor University

Research article

Keywords: Neonatal Near Miss, Proportion, Awi Zone, Ethiopia

Posted Date: August 21st, 2019

DOI: https://doi.org/10.21203/rs.2.13312/v1

License: (c) (i) This work is licensed under a Creative Commons Attribution 4.0 International License. Read Full License 


\section{Abstract}

Background: Neonatal mortality is a significant problem in many low-resource countries, yet for every death there are many more new-born who suffer a life-threatening complication but survive. Neonatal near miss has been proposed as a tool for assessment of quality of care in neonates who suffered any lifethreatening condition. However, there was limited evidence on magnitude of neonatal near miss and determinant factors in Ethiopia. The aim of this study was to assess proportion and associated factors of neonatal near miss among deliveries at Injibara General Hospital, Awi Zone, Northwest Ethiopia, 2019. Methods: Institutional based cross sectional study was conducted from February 1, 2019 to April 30, 2019 among 404 live births. Structured and pretested questioner used for mothers and structured checklist for neonates. Bivariate and multivariate logistic regressions model were fitted to identify factors associated with neonatal near miss. An adjusted odds ratio with $95 \%$ confidence interval (Cl) was computed to determine the level of significant. Result: Proportion of neonatal near miss was found to be $23.3 \%$ with 95\% Cl: (19.1\% -27.7\%). Primiparous[Adjusted odds ratio(AOR):2.01, 95\% Cl:(1.03-3.95)], referral linkage [AOR:3.23, 95\%Cl:(1.89-5.513)], maternal perception of reduced fetal movement[AOR:5.95, 95\%Cl:2.4714.33], premature rupture of membrane [AOR: $3.10,95 \% \mathrm{Cl}$ : (1.27-5.59)], prolonged labor [AOR: $3.00,95 \% \mathrm{Cl}$ : (1.28-7.06)], obstructed labor/cephalo-pelvic disproportion [AOR: 4.05; 95\% Cl: (1.55-10.57)] and nonreassuring fetal heart rate pattern [AOR: $3.75,95 \% \mathrm{Cl}$ : (1.69-8.33)] were significantly associated with neonatal near miss. Conclusion: Proportion of neonatal near miss in the study area was found to be higher than studies in WHO neonatal near miss systemic review. Strength referral linkage and efforts needed to continue compressive maternal and neonatal care to avoid preventable causes of neonatal morbidity and mortality.

\section{Background}

Neonatal near miss is defined as a newborn who presented a severe complication in the first 28 days of life almost died but survived during the neonatal period $[1,2]$.The near miss concept and indicators provide useful information to evaluate the quality of care and set priorities for further assessments and improvement of health care $[1,3]$.

Identification of neonatal near miss cases was based on two groups of criteria (pragmatic and management criteria). The pragmatic criteria; (Birthweight $<1750 \mathrm{~g}$, Apgar score $<7$ at 5 minutes and gestational age at birth < 33 complete weeks) and management criteria; ( parenteral antibiotic therapy up to 7 days and before 28 days of life, mechanical ventilation,nasal continuous positive airway pressure, intubation up to 7 days and before 28 days of life, phototherapy within 24 hours of life, cardiopulmonary resuscitation,use of vasoactive drugs, use of anticonvulsant drugs, use of surfactant, use of blood products, use of steroids for the treatment of refractory hypoglycemia, surgery, use of antenatal steroid,use of parenteral nutrition, identification of congenital malformation) $[2,4]$.

Near miss concept is a potentially useful approach to assess quality of newborn care but due to enormous variability of socio - demographic and technological advances in newborn care and registration of health information makes no consensus on establishment of criteria of neonatal near miss $[5,6]$. 
Globally 2.5 million newborns died in the first month of life in 2017 or about 7,000 every day. The majority of all neonatal deaths $75 \%$ occur during the first week of life and about 1 million newborns die within the first 24 hours. Neonatal deaths accounted for $47 \%$ of all under five deaths [7].

Neonatal near miss rate in in different studies revealed that 72.5/1,000 live births in WHO multicounty survey, 220/1000 live births in Northeastern Brazil and 39.2 / 1000 live births in Birth in Brazil survey [810].

According to EDHS 2016, Neonatal mortality declined from 49 deaths per 1,000 live births in 2000 to 29 deaths per 1,000 births in 2016 , a reduction of $41 \%$ over the past 16 years. While both, numbers and rates, have been lessening over the last 16 years, neonatal mortality accounts for an increasingly proportion of under five deaths[11].

Even though, Ethiopia settled priorities to reduce under five mortality,such as increase skilled birth attendants at birth,meeting the unmet need of family planning,improving quality of care,increase community based newborn care and expansion of quality facility new born care, increasing resources for health financing and increasing focus on research and innovation, still neonatal morbidity and mortality is unaccomplished [12].

There is limited evidence regarding to neonatal near miss concept in Ethiopia.Moreover no available studies regarding to neonatal mortality. Therefor this study aims to assess proportion and factors associated with neonatal near miss among deliveries at Injibara General Hospital, Awi Zone.

\section{Methods}

\section{Study design and setting}

Institutional based cross sectional study was conducted among 404 live births at Injibara General Hospital, Awi Zone, Amhara Region, Northwest Ethiopia from February 1, 2019 to April 30, 2019. Injibara town is the capital of the administrative center of Awi Zone. It is located about $447 \mathrm{~km}$ away from the capital city of Ethiopia, Addis Ababa and 118 km from Bahir Dar a city of Amhara National Regional State. Injibara General Hospital provides health service to more than 1.2 million populations and in its catchment area there are 46 health centers and 5 district hospitals. The hospital has different departments that provide outpatient service, inpatient service and operative theatre department.

Inclusion and exclusion criteria: All live birth neonates with their mothers and within 28 days of neonatal life were eligible to participate while neonates with gestational age less than 28 completed weeks,readmitted neonates and congenital anomalous were excluded.

\section{Sample size determination}


Single population proportion formula was used to determine the sample size. Considering $50 \%$ proportion of live births surviving life threating conditions during neonatal period at $5 \%$ margin of error $(w)$ and $95 \%$ $(\mathrm{Za} / 2=1.96)$ confidence level $(\mathrm{Cl})$. To compensate for non-responses, $5 \%$ of determined sample size was added and the final sample size was 404 .

\section{Sampling technique}

Systematic sampling technique was used to get all study unites. Based on the order of registration on postnatal log book for discharge, data at every other interval was collected from mothers and their live births up to desired sample were obtained.

\section{Operational definition}

Neonatal near miss was considered when the newborn faced at least one of the following proposed criteria but survived those complications;

Pragmatic criteria;

- Birth weight $<2500 \mathrm{~g}$,

- Gestational age $<37$ weeks

- 5th-minute Apgar score $<7$

Management criteria;

- Mechanical ventilation

- Cardiopulmonary resuscitation (CPR)

- Intubation

- Nasal continuous positive airway pressure(NCPAP)

- Parenteral antibiotics

- Use of parenteral nutrition

- Vasoactive drugs

- Phototherapy during the first 28 days

- Anticonvulsants

- Use of blood products

- Use of steroids for the treatment of refractory hypoglycemia

- Surgical procedures

- Use antenatal steroid

\section{Data collection procedure and quality assurance}


A combination of data collection methods was used. The data from mothers was collected by using pre tested interviewer-administered structured questionnaire which were adapted from literature reviews and maternal charts also reviewed for clarity of diagnosis and intervention. Data from their neonates was collected by using structured checklist adapted from different literatures which were developed for similar purpose by different authors. The verbal autopsy was used to collect information from individuals who provided health care service. Maternal data collection tool (questionnaire) was prepared first in English and then translated to a local language (Amharic and Agew) and then re-translated back to English to verify the consistency and content of the questionnaire. Data was collected by 5 BSc midwives and supervised by two senior BSc midwives.

Training was given for data collectors and supervisors regarding to the objectives of the study, method of data collection and significance of the study to prevent any confusion and have a common understanding about the study. Pre-test was conducted for $10 \%$ of sample size on other district hospital that have similar characteristics with the study population. Throughout the course of the data collection, interviewers was supervised and regular meetings was held between the data collectors, supervisor and the principal investigator together in which problematic issues arising from interviews was discussed and addressed. The collected data was reviewed and checked for completeness before data entry.

\section{Data analysis}

All collected questionnaires were checked manually for completeness and then coded and entered in to Epidata version 3.5 then exported in to SPSS (statistical packages for social science) version 20 for analysis.Discriptive statistics,binary and multivariable logistic regression analysis were used to identify associated factors. Variables having $p$-value $<0.20$ in the bivariate analysis was selected for the multivariate logistic regression model for adjustment of confounding effect between explanatory variables. Adjusted odds ratio with $95 \%$ confidence interval $(\mathrm{Cl})$ was computed and variables having P-value less than 0.05 in the multivariate logistic regression model was considered as statistically significant. Odds ratio was also used to determine the strength of association between independent variables and the outcome variable.

\section{Results}

\section{Socio-demographic characteristic of study subjects in Injibara General Hospital, Awi Zone, Northeast Ethiopia, 2019}

A total of 404 mothers with their live birth neonates were interviewed with a response rate of $100 \%$. Mothers of newborn were in the age group of $20-34$ years, $311(77 \%)$ with the mean age was (29 years \pm 5.4 SD). $99 \%$ of mothers were married and $97 \%$ of mothers were orthodox religious follower. $289(71.5 \%)$ were Agew ethnicity and nearly two third were urban residence, 254(63\%).Regarding to educational status, mothers were not attended formal education $150(37 \%)$. Two hundred forty five (61\%) of motheres were housewife. 


\section{Obstetrics and Gynecology characteristic of mothers of newborns}

All selected mothers of newborns had at list one ANC follow up visit. Women who had 1-3 ANC visit were $213(52.7 \%)$ and high proportion of neonatal near miss cases,57(60.6\%) was found in this category of ANC follow up visit. Twenty eight percent of mothers were primiparous. High rate of neonatal near miss cases were observed in primiparous 36(38.3\%). 148(36.6\%) of mothers of newborns were referred from other health institution, among them more than half $56(60 \%)$ of neonatal near miss cases were found. Obstetric complication during current pregnancy and labor-delivery were noted for $72(17.8 \%)$ and $89(22 \%)$ of mothers respectively [Table 1].

\section{Neonatal near miss characteristic}

A total of $94(23.3 \%)$ livebirth neonates were met the criteria of neonatal near miss. Among neonatal near miss selection criteria; mechanical ventilation was the most commonly identified criteria, 50(53\%) with proportion of $124 / 1000$ live births and $35(37 \%)$ of neonatal near miss cases were preterm birth, less than 37 completed weeks of gestation with proportion of 86.6/1000live births. Almost one third of neonatal near miss cases were low birth weight, 29(31\%) and accounts almost 82/1000 live births. More than half of neonatal near miss cases, 53(58\%) were faced more than one neonatal near miss criteria [Table 2].

\section{Factors associated with neonatal near miss}

Multivariate logistic regressions revealed that primiparous, referral linkage, premature rupture of membrane (PROM), maternal perception of reduced fetal movement, obstructed labor/cephalo-pelvic disproportion; prolonged labor and non-reassuring fetal heart rate pattern were significantly associated with neonatal near miss.

Women who were primiparous increased 2 times the odds of neonatal near miss as compared to mothers who were grand multiparous [AOR:2.06,95\% Cl:(1.06-3.98)].Women who were referred from other health institution increased 3 times the odds of neonatal near miss ( NNM) as compared to non-referral cases[AOR:3.23, 95\% Cl:(1.89-5.51)].

Of obstetric complications faced during current pregnancy; Premature rupture of membrane increased 3 times the odds of NNM [AOR: 3.10,95\% Cl:(1.27-7.59)]. Maternal perception of reduced fetal movement increased almost 6 times the odds of NNM as compared to their counter parts [AOR: 5.95, 95\%Cl:( $2.47-$ 14.33)].

Of obstetric complications during labor -delivery; women with prolonged labor ( $>24$ hours of labor) increased 3 times the odds of NNM as compared to delivery within 24 hours of labor [AOR: 3.00; 95 \%:( 1.28-7.06)]. Women with obstructed labor/cephalo-pelvic disproportion increased 4 times the odds of NNM as compared to normal labor [AOR:4.05; 95\%Cl:(1.55-10.57)]. Presence of non-reassuring fetal heart 
rate pattern increased almost 4 times the odds of NNM as compared to those who had normal range of fetal heart rate pattern during labor [AOR:3.75,95\% Cl:(1.69-8.33][Table 3].

\section{Discussion}

In this study the proportion of neonatal near miss was $23.3 \%$ with $95 \% \mathrm{Cl}$ : $(19.1 \%-27.7 \%)$. This finding is consistent with the finding of study in Northeastern Brazil 22\% [10].

This finding is high as compared to study done in WHO multicounty survey $7.25 \%$, Birth in Brazil survey $3.92 \%$, study in South of Brazil 3.3\%, and in Southeast Brazil 1.7\% $[8,9,13,14]$. Variation of neonatal near miss rate in WHO multicounty survey and Southeast Brazil was might be due to methodological difference and used only pragmatic criteria and also study in Birth in Brazil and study in South of Brazil was used only 4 selection items from management and pragmatic criteria.

In this study proportion of neonatal near miss is low as compared to study in Uganda $36.7 \%$, this is might be due to methodological difference and inclusion criteria were new-borns only from mothers with sever obstetric complication[15].

In this study high proportion of neonatal near miss criteria were observed for mechanical ventilation (53.2\%), gestational age less than 37completed week (37.2\%), birth weight $<2.5 \mathrm{~kg}(31 \%), 5$ minute APGAR Score $<7(22.3 \%)$ and use of parenteral antibiotics $(25.5 \%)$. This is in line with study in a systemic review on neonatal near miss, Northeastern Brazil, Birth in Brazil survey and study in South of Brazil $[2,8,10,13]$.

Primiparous was statistically associated with neonatal near miss, increased 2 times the odds of NNM as compared to grand multiparous [AOR: $2.06,95 \% \mathrm{Cl}:(1.06-3.98)]$. This result is in line with studies in Northeastern Brazil and Southeast Brazil $[10,14]$.This might be due to the fact that primiparous were high risk for malposition, malpresentation, prolonged labour, increased induction of labour, obstructed labor/cephalo-pelvic disproportion.

Obstetric complication during current pregnancy were showed statistically significant to neonatal near miss. Premature rupture of membrane increased 3 times the odds of NNM [AOR: 3.10, 95\%Cl: (1.27-7.59)] as compared to their counter parts. This might be due to the fact that premature rupture of membrane is usually leads to preterm labor which is at risk for birth asphyxia, chorioaminities, neonatal sepsis, pulmonary hypoplasia and cord prolapse. Different studies revealed that premature rupture of membrane is increased significantly the risk of maternal, fetal and neonatal morbidity and mortality resulting from obstetric complications $[16,17]$.

Women with reduced fetal movement during pregnancy increased almost 6 times the odds of NNM [AOR: $5.95,95 \% \mathrm{Cl}$ : (2.47-14.33)] as compared to mothers who did not perceive reduced fetal movement. This might be due to fetal compromised, utero-placental insufficiency, intrauterine growth restriction and abnormal amniotic fluid volume. Similarly different studies revealed that reduced fetal movement associated with poor prenatal outcomes those were preterm birth, perinatal birth injury, low birth weight, Iow APGAR score, increase rate of cesarean section, neonatal and fetal death $[18,19]$. 
Obstetric complications during labor- delivery were strongly associated with neonatal near miss. Women with obstructed labor /cephalo-pelvic disproportion increased 4 times the odds of NNM [AOR: 4.05, 95\%Cl:( $1.55-10.57)]$ as compared to their counter parts. This might be due to obstructed labor causes fetal hypoxia due to tonic uterine contraction that interferes with the uteroplacental circulation, intracranial hemorrhage due to super moulding of the head, birth trauma and infection.

Mothers with prolonged labor increased 3 times the odds of NNM [AOR: 3.00,95\% Cl:(1.28-7.06)] as compared to mothers who were delivered within 24 hours of labor. This might be due to abnormal progress of labor leads to fetal distress, early neonatal and fetal infection, birth trauma and fetal hypoxia due to diminished uteroplacental circulation.

Detected non reassuring fetal heart rate pattern increased almost 4 times the odds of NNM [AOR:3.75, 95\% $\mathrm{Cl}$ : (1.69-8.33)] as compared to detected reassuring fetal heart rate pattern. Supporting study in Indonesia revealed that survival of newborn from mothers without sever complications was better than that of newborn from mothers with obstetric complications[20] and studies in Brazil also revealed that maternal near miss were strongly associated with prematurity, neonatal asphyxia and early respiratory discomfort [21].

This finding is supported, studies in Jimma university specialised hospital and Dessie referral hospital, shows that obstetric complication during current pregnancy and complication during labor and delivery were strongly associated with adverse birth outcomes(low birth weight,preterm birth, low APGAR score and still birth)[22-24].

Referral linkage was significantly associated with neonatal near miss. This result is in line with study in Jimma university specialised hospital, revealed that referral of mothers with complications from other facility for delivery service was high risk for adverse pregnancy outcomes than mothers who were not referred[22].This is might be due to the fact that referral cases were from mothers who faced obstetric complications and needs timely and better intervention to avoid maternal and neonatal morbidity and mortality.

\section{Conclusion}

The proportion of neonatal near miss in the study area was found to be high. Statistically associated variables with neonatal near miss were primiparous, referral linkage, premature rupture of membrane, maternal perception of reduced fetal movement, prolonged labor, obstructed labor/cephalo-pelvic disproportion, and non-reassuring fetal heart rate pattern. Ensuring the continuum of compressive maternal care from pregnancy through delivery to avoid preventable causes of neonatal morbidity and mortality and creating good referral linkage with health facilities within its catchment areas including feedback providing.

\section{List Of Abbreviations}


NNM: Neonatal Near Miss, ANC: Ante Natal Care, EDHS: Ethiopia Demographic and Health Survey, WHO: World Health Organization, NICU: Neonatal Intensive Cares Unite, AOR: Adjusted Odds Ratio, COR: Crude Odds Ratio, APGAR: Appearance,Pulse,Grimace,Activity and Respiration.

\section{Declarations}

\section{Ethical approval and consent to participate}

Ethical clearance was obtained from the ethical review board of Bahir Dar University College of Medicine and Health Science and supporting letter was written to Injibara General Hospital, Awi Zone. Verbal informed consent was obtained from all mothers participanting in this study.

\section{Consent for publication}

Not Applicable

\section{Availability of data and materials}

When the ethics statement was obtained from Injibara General Hospital,we have agreed and signed not to publish the row data retrieved from the information of the mothers and their newborns. However, the datasets collected and analyzed for the current study is available from the corresponding author and can be obtained on a reasonable request.

\section{Competing interest}

We declare that there is no conflict of interest in this research

\section{Funding}

The author did not receive funding for this study

\section{Authors' contributions}

HG: raised the research idea, wrote the proposal, participated in designing the study, supervising data collection process, performed the statistical analyzes and writing the manuscript. MB: Participating in data analysis and revised drafts of the paper. SK and TH: reviewed and finalized them. All authors read and approved the final manuscript. 


\section{Acknowledgement}

We would like to thank Bahir Dar University for the approval of the ethical clearance and technical support of this study. We are also very grateful for supervisors, data collectors and study participants.

\section{Author details}

1Department of Midwifery, College of Health Science, Debre Tabor University, P. O.Box:272, Debre Tabor, Ethiopia.

2Department of Midwifery, College of Health Science, Bahir Dar University, P. O.Box:79, Bahir Dar, Ethiopia.

\section{Reference}

1.Santos JP, Cecatti JG, Serruya SJ, Almeida PV, Duran P, Mucio B, et al. Neonatal near miss: the need for a standard definition and appropriate criteria and the rationale for a prospective surveillance system. Clinics, 2015. 70(12): 820-826.

2.Santos JP, Pileggi-Castro C, Camelo JS, Silva AA, Duran P, Serruya SJ, et al. Neonatal near miss: a systematic review. BMC pregnancy and childbirth, 2015. 15: 320.

3.Pileggi C, Souza JP, Cecatti JG, Faúndes A.Neonatal near miss approach in the 2005 WHO Global Survey Brazil. Jornal de pediatria(Rio J), 2010. 86(1): 21-26.

4.Surve S, Chauhan S, Kulkarni R. Neonatal near miss review: Tracking its conceptual evolution and way forward. Current Pediatric Research, 2017.

5.Say L. Neonatal near miss: a potentially useful approach to assess quality of newborn care. Jornal de pediatr, 2010. 86(1): 1-2.

6.Avenant T. Neonatal near miss: a measure of the quality of obstetric care. Best Pract Res Clin Obstet Gynaecol, 2009. 23: 369-374.

7.United Nations Inter-agency Group for Child Mortality Estimation (UN IGME), Levels \& Trends in Child Mortality: Report 2017, Estimates Developed by the UN Inter-agency Group for Child Mortality Estimation', United Nations Children's Fund, New York, 2017.

8. Silva AAMd, Leite ÁJM, Lamy ZC, Moreira MEL, Gurgel RQ, Cunha AJ,Leal MD. Neonatal near miss in the Birth in Brazil survey. Cadernos de saude publica, 2014. 30: 182-191.

9.Pileggi -Castro C, Camelo Js Jr, Perdoná GC, Mussi- Pinhata MM, Cecatti JG, Mori R, et al. Development of criteria for identifying neonatal near-miss cases: analysis of two WHO multicountry cross sectional studies. Bjog: An International Journal of Obstetrics \& Gynaecology, 2014. 121: 110-118. 
10. de Lima THB, Katz L, Kassar SB, Amorim MM. Neonatal near miss determinants at a maternity hospital for high-risk pregnancy in Northeastern Brazil: a prospective study. BMC pregnancy and childbirth, 2018. 18(1): 401.

11. Central Statistical Agency (CSA) [Ethiopia] and ICF. Ethiopia Demographic and Health Survey 2016. Key Indicators Report. Addis Ababa, Ethiopia, and Rockville, Maryland, USA. CSA and ICF, 2016.

12. Ministry of Health Ethiopia, PMNCH, WHO, World Bank, AHPSR and participants in the Ethiopia multistakeholder policy review (2015). Success Factors for Women's and Children's Health: Ethiopia.

13. Silva GA, Rosa KA, Saguier ESF, Henning E, Mucha F, Franco SC. A populational based study on the prevalence of neonatal near miss in a city located in the South of Brazil: prevalence and associated factors. Revista Brasileira de Saúde Materno Infantil, 2017. 17(1): 159-167.

14. Kale PL, Mello-Jorge MHPd, Silva KSd, Fonseca SC. Neonatal near miss and mortality: factors associated with life-threatening conditions in newborns at six public maternity hospitals in Southeast Brazil. Cadernos de saude publica, 2017. 33(4): e00179115.

15.Nakimuli A, Mbalinda SN, Nabirye RC, Kakaire O, Nakubulwa S, Osinde MO, et al. Still births, neonatal deaths and neonatal near miss cases attributable to severe obstetric complications: a prospective cohort study in two referral hospitals in Uganda. BMC pediatrics, 2015. 15: 44.

16. Kassa EM, Sirak B. Maternal and perinatal outcome of pregnancies with preterm premature rupture of membranes (pprom) at tikur anbessa specialized teaching hospital, addis ababa, ethiopia. Ethiopian medical journal, 2015. Jun 4:52(4).

17. Endale T, Fentahun N, Gemada D, Hussen MA. Maternal and fetal outcomes in term premature rupture of membrane. World journal of emergency medicine, 2016. 7(2): 147.

18. Poojari VG, Kumar SS, Vasudeva A. Obstetric and neonatal outcome among women presenting with reduced fetal movements in third trimester. Int J Reprod Contracept Obstet Gynecol, 2018. 7: 88-93.

19.McCarthy CM, Meaney S, O'Donoghue K. Perinatal outcomes of reduced fetal movements: a cohort study. BMC pregnancy and childbirth, 2016. 16(1): 169.

20.Anggondowati T, El-Mohandes AA, Qomariyah SN, Kiely M, Ryon JJ, Gipson RF, et al. Maternal characteristics and obstetrical complications impact neonatal outcomes in Indonesia: a prospective study. BMC pregnancy and childbirth, 2017. 17: 100.

21.Nardello DM, Guimarães AM, Barreto ID, Gurgel RQ, Ribeiro ER, Gois CF. Fetal and neonatal deaths of children of patients classified as near miss. Revista brasileira de enfermagem, 2017. 70: 104-111.

22. Yeshialem E, Alemnew N, Abera M, Tesfay A. Determinants of Adverse Pregnancy Outcomes among mothers who gave birth from Jan1-Dec 31/2015 in Jimma University Specialized Hospital, Case control study. Med Clin Rev, 2016. 3(4): 22. 
23. Cherie N, Mebratu A. Adverse Birth Out Comes and Associated Factors among Delivered Mothers in Dessie Referral Hospital, North East Ethiopia. J Women's Health Reprod Med, 2017. 1(1): 1-6.

24. Fantu S, Segni H, Alemseged F. Incidence, causes and outcome of obstructed labor in jimma university specialized hospital. Ethiopian journal of health sciences, 2010. 20(3).

\section{Tables}

Table 1: Obstetric characteristics of the mothers of newborns at Injibara General Hospital, Awi Zone, Northwest Ethiopia, 2019

\begin{tabular}{|c|c|c|}
\hline Variables $(n=404)$ & $\begin{array}{l}\text { Selected mothers with } \\
\text { their live births } \\
\text { N (\%) }\end{array}$ & $\begin{array}{l}\text { Neonatal near miss }(\mathrm{n}=94) \\
\mathrm{N}(\%)\end{array}$ \\
\hline \multicolumn{3}{|l|}{ ANC follow-up } \\
\hline $1-3$ & $213(52.7)$ & $57(60.6)$ \\
\hline$>=4$ & $191(47.3)$ & $37(39.4)$ \\
\hline \multicolumn{3}{|l|}{ Parity } \\
\hline 1 & $113(28)$ & $36(38.3)$ \\
\hline $2-3$ & $155(38.4)$ & $23(24.5)$ \\
\hline $4-5$ & $96(23.8)$ & $23(24.5)$ \\
\hline$>=6$ & $40(9.9)$ & $12(12.7)$ \\
\hline \multicolumn{3}{|l|}{ History of abortion } \\
\hline Yes & $45(11)$ & $9(9.6)$ \\
\hline No & $359(89)$ & $85(90.4)$ \\
\hline \multicolumn{3}{|l|}{ History of still birth } \\
\hline Yes & $22(5.4)$ & $6(6.4)$ \\
\hline No & $382(94.5)$ & $88(93.6)$ \\
\hline \multicolumn{3}{|c|}{ History of obstetric complication during pregnancy } \\
\hline Yes & $72(17.8)$ & $42(44.7)$ \\
\hline No & $332(82.2)$ & $52(55.3)$ \\
\hline \multicolumn{3}{|c|}{ History of obstetric complication during labor -delivery } \\
\hline Yes & $89(22)$ & $54(57.4)$ \\
\hline No & $315(78)$ & $40(42.6)$ \\
\hline \multicolumn{3}{|c|}{ Referral from other health institution } \\
\hline Yes & $148(36.6)$ & $56(60)$ \\
\hline No & $256(63.4)$ & $38(40)$ \\
\hline
\end{tabular}

Table 2: Criteria for neonatal near miss among live births at Injibara General Hospital, Awi Zone, Northwest Ethiopia, 2019 ( $\mathrm{n}=404)$ 


\begin{tabular}{|c|c|c|}
\hline Criteria & $\begin{array}{l}\text { Proportion of NNM in each } \\
\text { category(n=94) } \\
\qquad N(\%)\end{array}$ & $\begin{array}{l}\text { Proportion of NNM/1000 } \\
\text { live births }\end{array}$ \\
\hline $\begin{array}{l}\text { Gestational age less than 37completed } \\
\text { weeks }\end{array}$ & $35(37.2)$ & 86.6 \\
\hline Weight less than $2.5 \mathrm{~kg}$ & $29(31)$ & 71.8 \\
\hline 5 minute APGAR Score $<7$ & $21(22.3)$ & 51.9 \\
\hline Mechanical ventilation & $50(53.2)$ & 124 \\
\hline Cardiopulmonary resuscitation (CPR) & $12(12.8)$ & 29.7 \\
\hline Intubation & $4(4.2)$ & 1 \\
\hline $\begin{array}{l}\text { Nasal continuous positive airway } \\
\text { pressure(NCPAP) }\end{array}$ & $11(11.7)$ & 27 \\
\hline Parenteral antibiotics & $24(25.5)$ & 59 \\
\hline Use of parenteral nutrition & $13(13.8)$ & 32 \\
\hline Vasoactive drugs & $5(5.3)$ & 12.4 \\
\hline Phototherapy during the first 28 days & $2(2.1)$ & 5 \\
\hline Anticonvulsants & $2(2.1)$ & 5 \\
\hline $\begin{array}{l}\text { Use of steroids for the treatment of } \\
\text { refractory hypoglycemia }\end{array}$ & $3(3.2)$ & 7.43 \\
\hline Use antenatal steroid & $5(5.3)$ & 12.4 \\
\hline
\end{tabular}

N.B; this cannot be sum up to $100 \%$ because of multiple intervention were possible

Table 3: Multiple logistic regression analysis on factors associated with neonatal near miss at Injibara Gener Hospital, Awi Zone, Northwest Ethiopia, 2019 


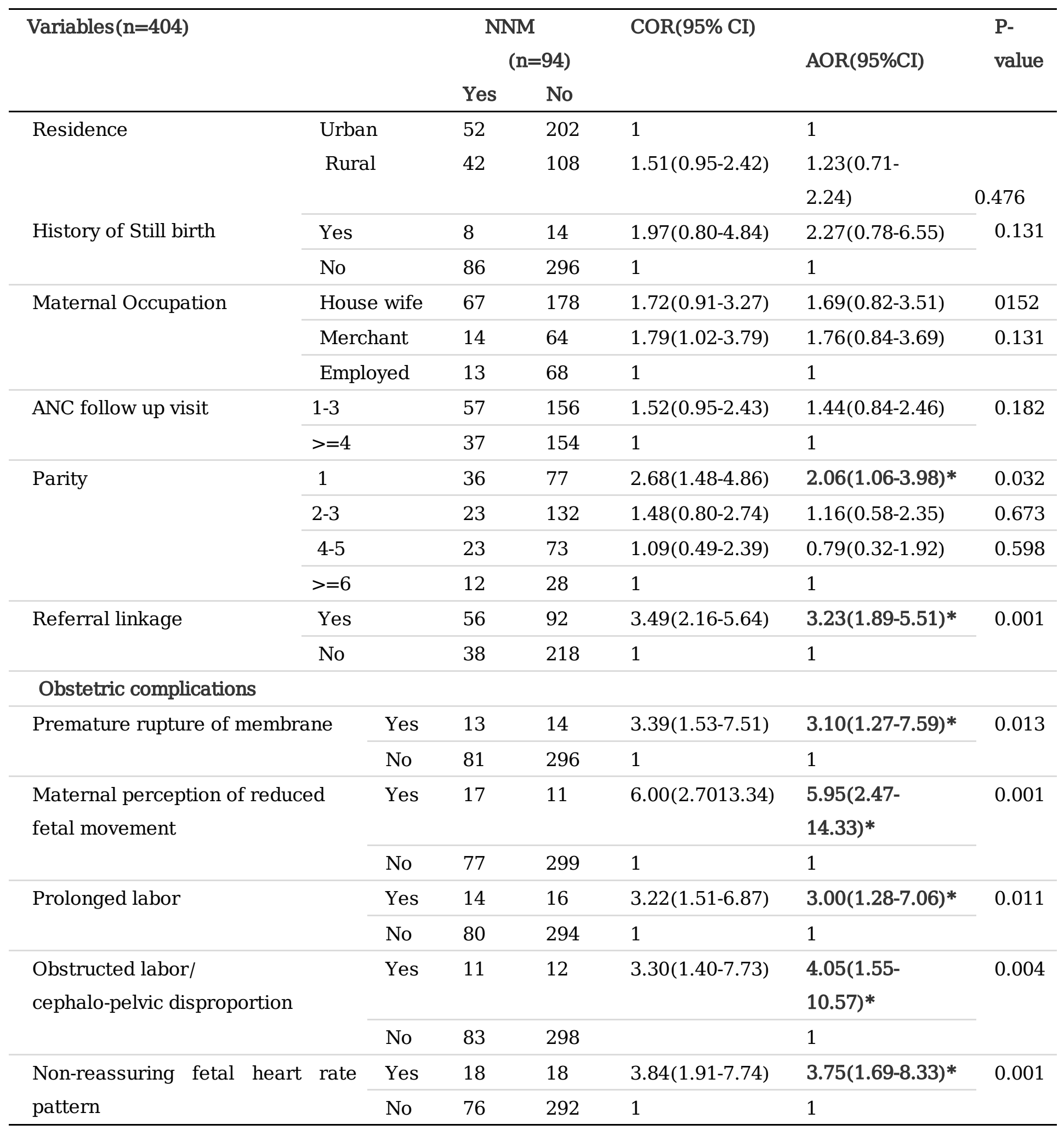

*with italicized value indicated that a statistically significant association at 95\% Confidence interval (CI) that did not include 1 in the interval

$1=$ reference category

Hosmer and Lemeshow test for multivariable logistic regression $=0.66$ 